\title{
An Estimation of the Diet of the Species Serranus Scriba (Linnaeus, 1758) in the Area of Nisiopi, in South-West
}

\section{Lesvos}

\author{
Makri Vasiliki \\ Department of Marine Sciences, the University of the Aegean, Mytiline 81100, Greece
}

\begin{abstract}
The current study examines the diet of Serranus scriba (Osteichtyes of the family Serranidae). This species of fish was collected using gillnets at the sea near the village of Sigri which is located in the South-West side of the island of Lesvos. Based on the results, Serranus scriba is characterized as carnivorous with a preference in Decapods. Also, the GSI (Gonado Somatic Index), HSI (Hepato Somatic Index) and CF (Condition Factor) index were calculated, with the estimation of numbers of females and males and separation of mature stages using the scale Nikolsky. Majority of the individuals of this species are females with a ratio of $88 \%$ versus male with $12 \%$. And based on the calculation of indicators they are characterized quite mature, with good percentage of stored energy and good condition of healthiness. Moreover, it is concluded, based on the above analysis, in the area there was plenty of food for the individuals of this species in their breeding season (April-August breeding season).
\end{abstract}

Key words: Serranus Scriba, fish, Lesvos, Mytiline GSI (Gonado Somatic Index), HSI (Hepato Somatic Index), CF (Condition Factor), diet.

\section{Introduction}

The Serranidae family consists of 537 species which belong to 75 genera. Serranus scriba (Fig. 1.1) could be found from the Straits of Gibraltar to Senegal and the Canary Islands. It also ranges from the Mediterranean and Black Seas, to the coasts of Portugal and Spain to the bay of Biscay. This species is very abundant in the marine reserves of the Canary Islands. Serranus scriba lives in shallow, rocky bottoms from the shore to $150 \mathrm{~m}$ in depth. This species grows quite slowly and lives very long. This fish can be caught by artisanal fisheries using hook and line and trawls, but this is not a major threat globally [15].

Their bodies are elongated and their heads are pointed. Their colors are gray, purple and reddish brown with 5-7 dark vertical stripes on the body side of which the two latters are joined to the lower body.

\footnotetext{
Corresponding author: Makri Vasiliki, environmentalist-marine biologist (master in progress), main research field: biological oceanography.
}

The top of the head is hollow and there are several narrow wavy blue lines and red spots. On the fins there are red dots. It is hermaphroditic. Their breeding season is from April to August (Mediterranean) [15].

\section{Materials and Methods}

\subsection{Materials}

This species of fish was collected using gillnets at the sea near the village of Sigri which is located in the South-West side of the island of Lesvos. The Table 2.1 presents the stations of sampling and the Fig. 2. 1 shows the locations of sampling stations [9].

In Sigri, there is the Petrified Forest, which belongs to the Global Geoparks Network of UNESCO (United Nations Educational Scientific and Cultural Organizations) and the Islet Nisiopi which is protected as a Site of Outstanding Natural Beauty (2000) and is under the network of Natura (2000) [9].

The experimental fishery was conducted by hiring professional fishing vessel (Fig. 2.2). The gear selected was trammel nets with dimensions which possess 

Area of Nisiopi, in South-West Lesvos.

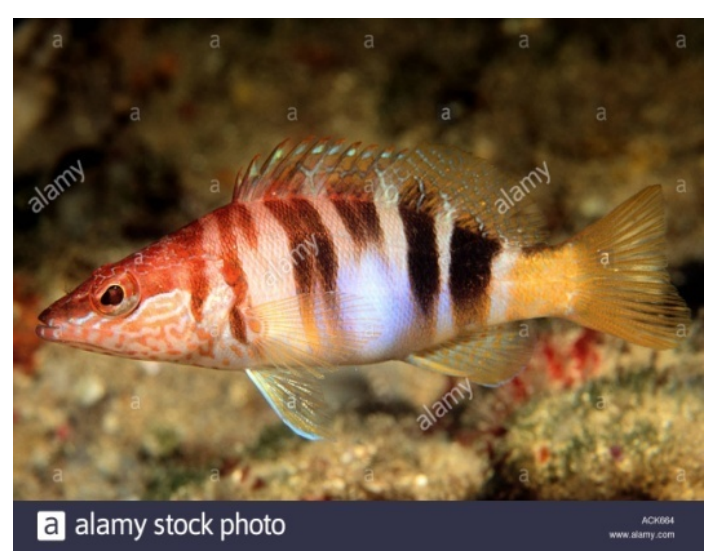

Fig. 1.1 Painted comber (Serranus scriba, Linnaeus 1758) (Source: www.alamy.com).

Table 2.1 The stations of sampling.

\begin{tabular}{lllll}
\hline & & & G. Latitude (DD) & G. Longitude (DD) \\
\hline \multirow{4}{*}{ Experimental fishing } & F1 & Southerly of Kavalourou & 39,197104 & 25,823177 \\
& F2 & Southerly of Plaka & 39,202766 & 25,850715 \\
& F3 & Eastly of Nisiopi & 39,218577 & 25,845043 \\
& F4 & NorthWest of Nisiopi & 39,225643 & 25,838437 \\
\hline
\end{tabular}

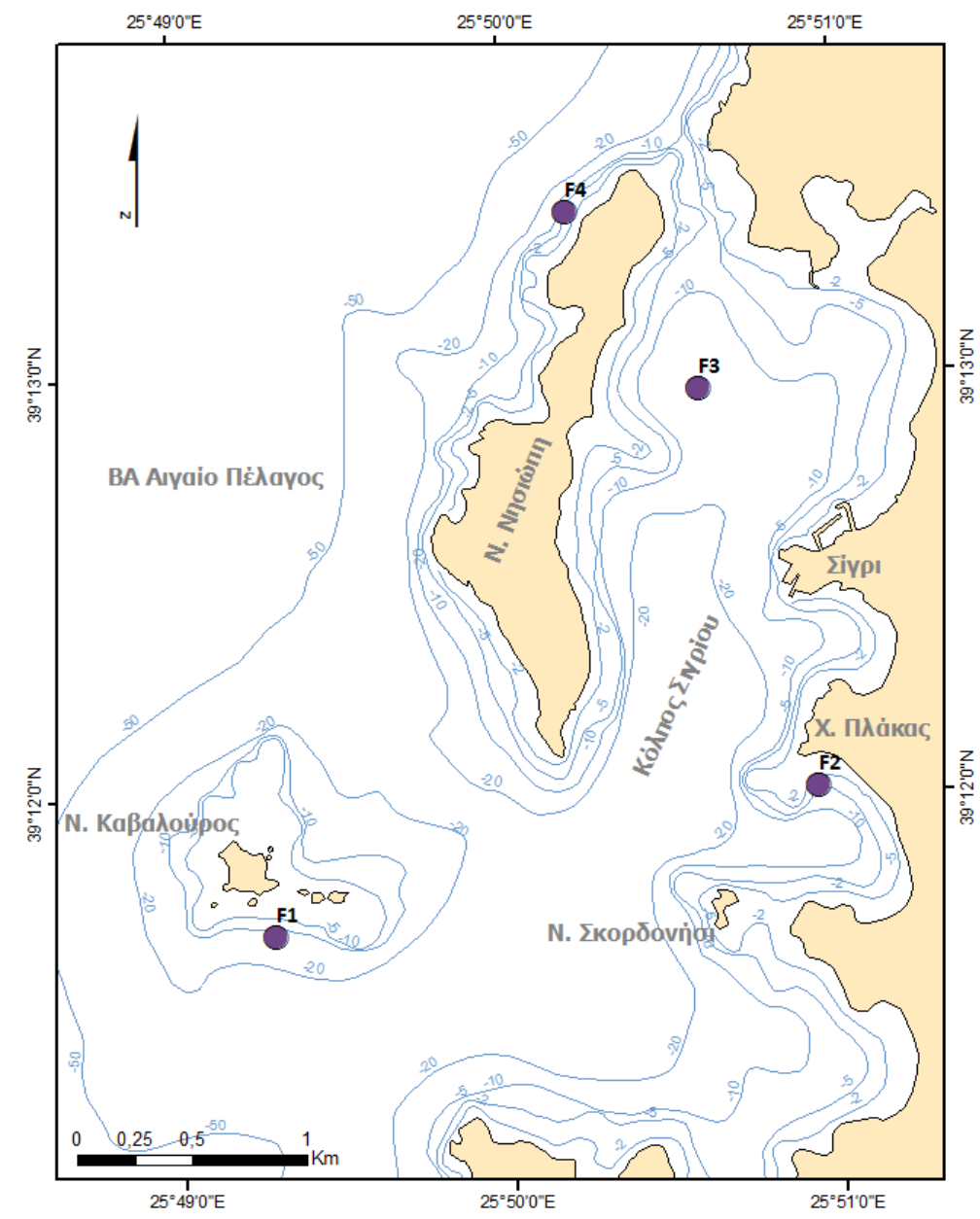

Fig. 2.1 The locations of sampling stations. 


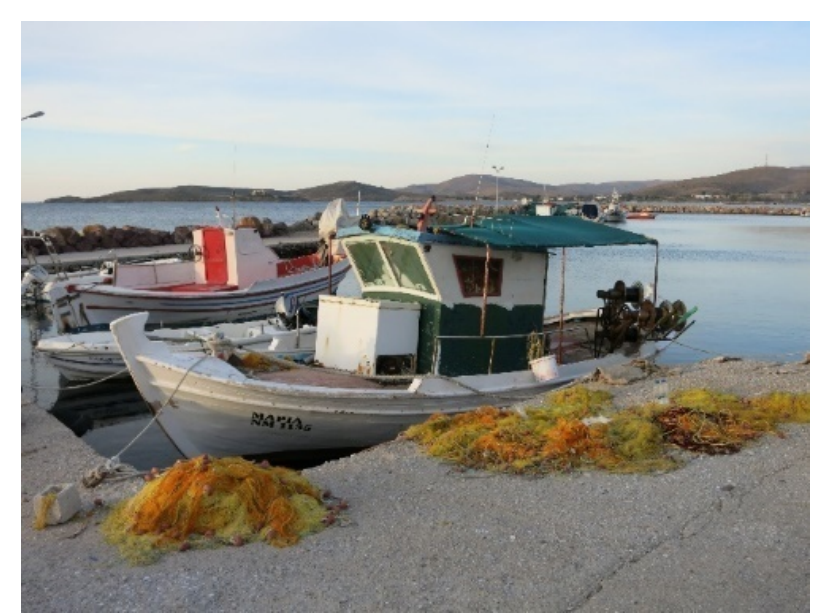

Fig. 2.2 The professional fishing boat which used in the field work of experimental fisheries.



Fig. 2.3 Trammel nets as a fishing tool (Source: www.yen.gr).

length of 1,000 fathoms $(1,829 \mathrm{~m})$, height of $1.3 \mathrm{~m}$ and $22 \mathrm{~mm}$ eye opening (Fig. 2.3). The option of the gear contributed to the fact that most of the seafloor of the study area was covered by seagrass meadows, which are under the Directive "Habitats of the EU" (92/43/EEC, ANNEX I), the priority habitat protected [9].

Trammel nets are static tools, which are not drawn to capture their organizations. They consist of three pieces of netting which are joined by a common rope cork (floatline) and a common rope with weights (leadline). Moreover, trammel nets can capture the fishes in three different ways [2].

The fish may become entangled in the loop which created by the polish with the nets and wedged in a mesh around the body in the first way. Nets may also be kinked in gills of the fishes and the last way that is the fish nets may be kinked with its tooth or on spines of fins or on some other part of the fish [2].

Trammel nets have small selectivity, because they can capture wider range of undersized fishes. The manner in which are designed in conjunction with ballasting and buoyancy gives the ability to be used in a range of depths which extends from the coastal waters up to the bottom, as a result collecting the fishes which live on the seabed and the surface of sea (demersal, benthic and pelagic species) [2].

\subsection{Maturity}

Gonads were removed from each individual. And from its coarse remark for segregation in male and female one can also observe their maturity.

The determination of the sex of the individual was based on the color and the shape of the gonads. The gonads which were reddish belonged to the females, in contrast with the color of gonads of males which were white. Furthermore, the concave shape declares female gonads unlike the less concave shape that declares male gonads.

Stages of maturity were separated according to the Table 2.2.1 (theory of Nicolsky, 1976) [6].

The current study uses the following stages (Table 2.2.2).

At this sample, there were no individuals at stage 1 which means that there were not immature individuals.

\subsection{Stomach Contents}

At this stage, the stomach of each individual was thawed, and the total weight of the each stomach was weighted. An incision was made with careful moves in the stomach and the contents were removed. Also, the stomach of each individual was weighted empty.

Table 2.2.1 Stages of maturity.

\begin{tabular}{ll}
\hline Stages: 123 & Fishes were characterized immature \\
\hline Stages: 45 & Fishes were characterized mature \\
Stage: 6 & Fishes were calved (spent) \\
\hline
\end{tabular}


Table 2.2.2 Stages of maturity.

\begin{tabular}{ll}
\hline Stage 1 & Immature \\
\hline Stage 2 & Resting \\
Stage 3 & Developing \\
Stage 4 & Maturing \\
Stage 5 & Mature \\
\hline
\end{tabular}

In the end, the contents of stomachs were observed with a microscope for the determination of food items which were found. Moreover, an empty stomach was considered when there was little food residues which could not be recognized or only gastric juices were found.

The parasites were not taken into account in the study of stomach contents. Determination of food items was conducted using clavicles [1].

\subsection{Fertility Parameters-Indicators}

GSI (Gonado Somatic Index) is the ratio of the weight of the gonad to body weight and used to assess the reproductive condition of fish $[13,16]$. Reproduction is the most critical stage in the life cycle of a species that determines its survival.

Also, the GSI referred to the relationship between the weight of the gonads and the whole weight of the fish [13]:

$$
G S I=\left(W_{g} / B\right) * 100
$$

$\mathrm{Wg}=$ weight of gonads, $\mathrm{B}=$ total liquid weight.

HSI (Hepato Somatic Index) is the ratio of liver weight to body weight [13]. It gives an indication about the state of energy reserves in an animal. In a poor environment the fishes have usually small livers. It has been reported that HSI be reduced in fishes which exposed to high concentrations of Cadmium and Zinc. It is an indirect measure of food and energy condition and the fish growth.

Furthermore, based on the value that gives the HIS season, the fish spawning can be observed:

$$
H S I=\left(W_{L} / B\right) * 100
$$

$\mathrm{W}_{\mathrm{L}}=$ weight of the livers and $\mathrm{B}=$ total liquid weight [13].
CF (Condition Factor) index is calculated by using the body weight and the standard length of the fish, and it is used to compare the growth conditions of fishes. A high strength coefficient reflects the good quality of the environment and a low index reveals a deterioration of environmental quality [10]:

$$
C F=\left(W / L s^{3}\right) * 100
$$

$\mathrm{W}=$ total liquid weight and Ls $=$ Standard length.

\subsection{Emptiness of Stomachs}

Also, the emptiness of each stomach was calculated by using the C.R index, of each individual in order to assess the rate of empty stomach in each individual according to Eq. (4) [4]:

$$
\text { C.R }=100 * N_{p} /\left(N_{p}+N_{v}\right)
$$

$\mathrm{Np}=$ number of empty stomachs;

$\mathrm{Nv}=$ number of full of food stomachs;

A stomach was considered empty when contained only gastric juices.

\section{Results and Discussion}

Based on these results, this species preferred Crustaceans for their diet. Fishes were second in preference.

In this Chart, the results show that the majority of the females are very mature in contrast with the males of the sample that were resting. Also, there were no immature individuals.

The majority of the sample were females.

Based on GSI (Gonado Somatic Index), the majority of the sample is in reproduction period. The HSI (Hepato Somatic Index) was in normal levels and the $\mathrm{CF}$ (Condition Factor) was very high.

Finally, based on the C.R Index the sample was well fed. 


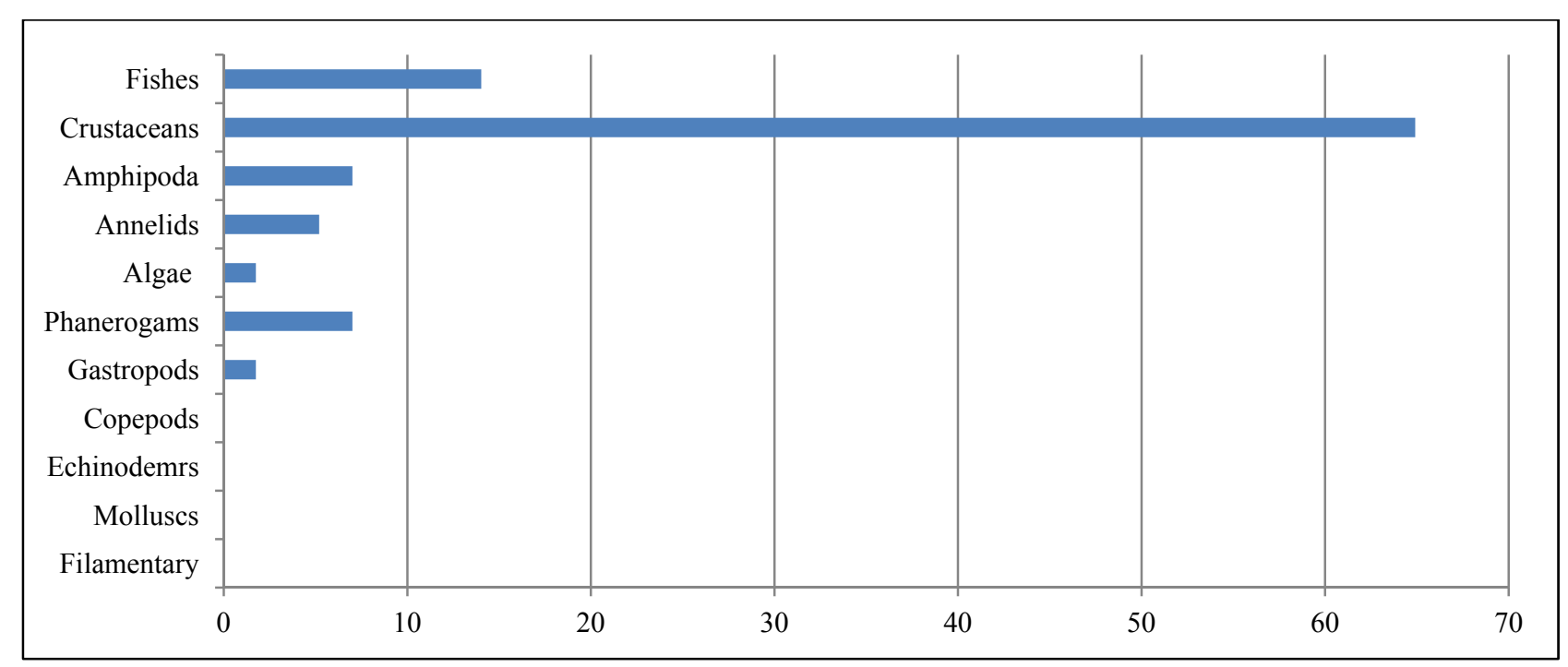

Chart 3.1 Frequency of incidence of kind of food in stomachs.

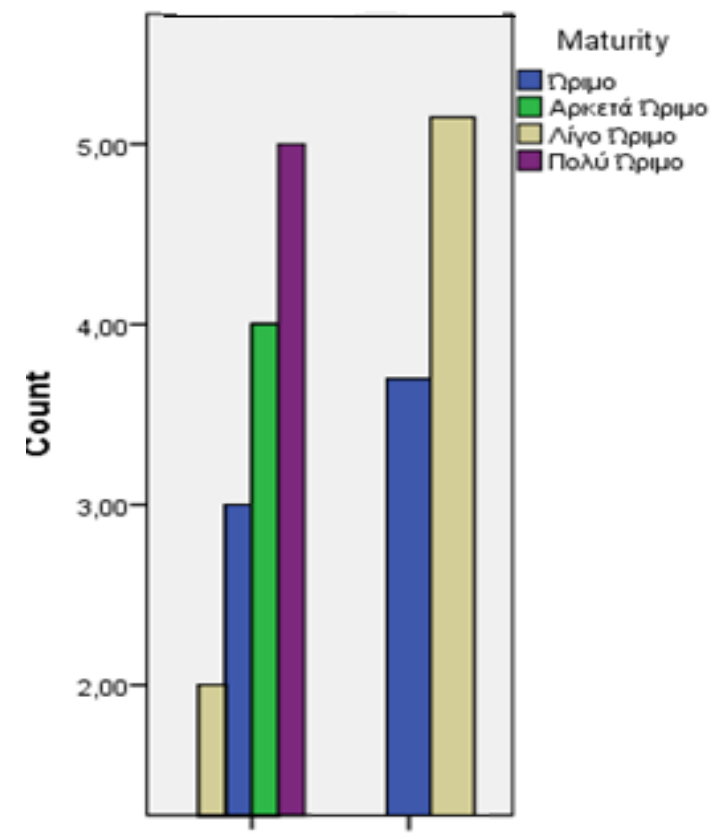

Chart 3.2 The distribution of stages of gonads (female-right, male-left), (blue-developing, green-maturing, yellow-resting, and purple-mature).

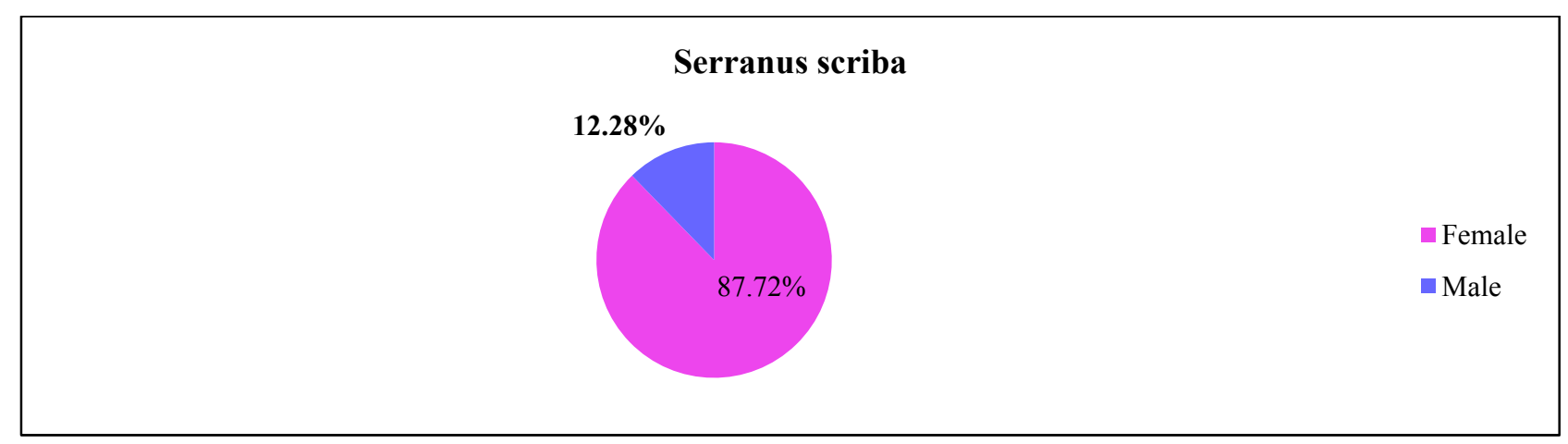

Chart 3. 3 The distribution of number of Serranus scriba. 




Chart 3.4 Estimation of GSI, HSI and CF.

Table 3. 5 Calculation of C.R Index.

\begin{tabular}{ll}
\hline Species & C.R Index \\
\hline Serranus scriba & $24.5 \%$ \\
\hline
\end{tabular}

\section{Conclusion}

This species is characterized as carnivorous with a special preference in Decapods. In the stomach contents, the majority were found to be crustaceans which, after identification, belonged to genus Galatheo (Fig. 4.1) and Liocarcinus, Osteichtyes residues which belonged to Blenidae and Serranidae family and one Osteichthys that after identification, it has been concluded, that it belonged to M. surmuletus.

Also, algae and phanerogams which were found in some stomachs are not trophic contents. But due to the fish trying to catch the quarry, it ended being captured together with the prey. This shows that the individuals of this species live in rocky bottoms which are covered with algae $[1,3]$.

In this study, the estimation of trophic level was done by means of food contents which were found in the stomachs of the individuals rather than from the composition of the diet. As for the determination of the trophic level of this species, the software TrophLab2K was used [14].

According to the trophic levels, the individuals of Serranus scriba were categorized into food groups (Fig. 4.1 \& Table 4.2) [12, 14].

As shown, on the chart 3.2, which based on the separation of maturity stages of Nikolsky scale [6], females were mature, in majority, which means that the individuals were in breeding season (April-August breeding season). Concerning the males, the majority of them were little mature. In general, individuals of this species are females with a ratio of $88 \%$ versus male with $12 \%$. The situation of the majority of females in samples is created by the behavior and the morphology of each individual separately. These include factors like age, available food, competition and other unknown factors $[3,7,8]$.

Also, the very important things are the fishing gear's selectivity and the fishing effort which differs between females and males by discriminating and targeting males because of their body (males usually are heavier and bigger than females) $[3,7]$.

GSI is used in fisheries biology to determine the time of maximum reproductive activity. Because of the calculation of the GSI, the species presents normal reproductive activity rates $[6,13]$.

The calculation of HSI used to show the condition of the fish, which means the percent of energy and food, as a result the observation of rate at which it is increased. This happens because the liver is storage of energy, which is stored in the form of glycogen, in periods when the fish receives large amounts of food (high rate of feeding). 




Fig. 4.1 Galatheo.

Table 4.1 The ranking of Serranus scriba according to the software TrophLab2K.

\begin{tabular}{lll}
\hline Species & Value & Trophic level \\
\hline S. scriba & 3.8 & Carnivorous with a special preference in Decapods (Crustaceans) \\
\hline
\end{tabular}

Table 4.2 The species categorized into food groups accordance with the following table.

\begin{tabular}{ll}
\hline Food Groups & Troph \\
\hline Herbivorous & $(2.0<\mathrm{TROPH}<2.1)$ \\
Omnivorous with preference in plants & $(2.1<\mathrm{TROPH}<2.9)$ \\
Omnivorous with preference in animals & $(2.9<\mathrm{TROPH}<3.7)$ \\
Carnivorous with preference in decapods & $(3.7<\mathrm{TROPH}<4.0)$ \\
Carnivorous with preference in fishes & $(4.0<\mathrm{TROPH}<4.5)$ \\
\hline
\end{tabular}

The values from the calculation of HSI are high, which means that this species is in good condition and with big growth. This may be due to the absence of competition in the region and the existence of a large rate of food.

CF index shows the condition of health of fish which is very important in body growth. Since the calculation of the CF the individuals have a high value of CF which means these are healthy and once again. And it confirmed that in the area the competition for food were small and there was no shortage of food [10].

\section{References}

[1] Beyer, J. E. 1998. "Stochastic Stomach Theory of Fish: An introduction." Ecological Modelling 114 (1): 71-93.

[2] Christopoulos, K. 2005. Marine Fishing: Techniques of Fishing. Publishing Christaki, B' Version, Athens, Page 287.

[3] Hughes, R. N. 1997. Behavioural Ecology of Teleost Fishes. Oxford University Press, Oxford.

[4] Hynes, H. B. N. 1950. "The Food of Fresh-Water Sticklebacks (Gasterosteus Aculeatus and Pygosteus Pungitius), with a Review of Methods Used in Studies of the Food of Fishes." Journal of Animal Ecology 19:
$36-58$.

[5] Koutrakis, E. T., Kallianiotis, A. A. and Tsikliras, A. C. 2004. "Temporal Patterns of Larval Fish Distribution and Abundance in a Coastal Area of Northern Greece." Scientia Marina 68 (4): 585-95.

[6] Tsikliras, A. C. 2004. "Biology and Population Dynamics of Round Sardinella (Sardinella Aurita Valenciennes, 1847) in Kavala Gulf (Northern Aegean Sea, Greece)." Ph.D. thesis, Aristotle University of Thessaloniki, Greece.

[7] Kaiser, M. J. and Hughes, R. N. 1993. "Factors Affecting the Behavioural Mechanisms of Diet Selection in Fishes.' Marine and Fresh Water Behaviour and Physiology 23 (1-4): 105-18.

[8] Kohler, C. C., and Ney, J. J. 1982. "A Comparison of Methods for Quantitative Analysis of Feeding Selection of Fishes." Environmental Biololy of Fishes 7 (4): 363-8.

[9] Makri, V. 2015. “ An Estimation of Morphometry and Diet of the Different Fish Species (Spicara Maena, Serranus Scriba, Mullus Surmuletus, Symphodus Tinca, Chromis Chromis, Scorpaena Scrofa, Scorpaena Porcus, Diplodus Vulgaris, Diplodus Annularis and Labrus Merula) in the Area of Nisiopi, South-West Lesvos." Undergraduate Thesis, University of the Aegean, Mytiline.

[10] Nash, R. D. M., Valencia, A. H., and Geffen, A. J. 2006. "The Origin of Fulton's Condition Factor-Setting the Record Straight. ' Fisheries 31 (5): 236-8. 
Area of Nisiopi, in South-West Lesvos.

[11] Nelson, J. S., Grande, T. C., and Wilson, M. V. 1994. Fishes of the World-Third Edition. New York: John Wiley and Sons.

[12] Pauly, D., and Sa-a, P. 2000, "Estimating Trophic Levels from Individual Food Items.” Fish Base 185.

[13] Sadekarpawar, S., and Parikh, P. 2013. "Gonadosomatic and Hepatosomatic Indices of Freshwater Fish Oreochromis Mossambicus in Response to a Plant Nutrient. " World Journal of Zoology 8 (1): 110-8.

[14] Stergiou, K. I., and Karpouzi, V. S. 2003. "The
Relationships between Mouth Size and Shape and Body Length for 18 Species of Marine Fishes and their Trophic Implications.' Journal of Fish Biology 62 (6): 1353-65.

[15] Tortonese, E., Whitehead, P. J. P., Bauchot, M. L., Hureau, J. C., and Nielsen, J. 1986. Fishes of the North-Eastern Atlantic and the Mediterranean. Volumn 3. United Nations Educational Scientific and Cultural Organization.

[16] Wooton, R. 2012. Ecology of Teloleost Fishes, Springer Science and Business Meida. 